\title{
An Investigation into the Response of GFRP-Reinforced Glue-Laminated Tudor Arches
}

\author{
S. Alshurafa, ${ }^{1}$ H. Alhayek, ${ }^{1}$ and F. Taheri ${ }^{2}$ \\ ${ }^{1}$ Department of Civil Engineering, University of Manitoba, 15 Gillson Street Winnipeg, MB, Canada MB R3T 2N2 \\ ${ }^{2}$ Department of Civil and Resource Engineering, Dalhousie University, 1360 Barrington Street, Halifax, NS, Canada B3J 1Z1
}

Correspondence should be addressed to F. Taheri, farid.taheri@dal.ca

Received 20 July 2011; Accepted 12 March 2012

Academic Editor: Muhammad Hadi

Copyright ( $) 2012$ S. Alshurafa et al. This is an open access article distributed under the Creative Commons Attribution License, which permits unrestricted use, distribution, and reproduction in any medium, provided the original work is properly cited.

\begin{abstract}
This paper presents the results of an experimental and computational investigation tailored to examine the response of glass fiber-reinforced-plastic-(GFRP-) reinforced glue-laminated curved beams and arches. The main objective was to ascertain the viability of GFRP as an effective reinforcement for enhancing the load carrying capacity and stiffness of such curved structures. The study included optimization of the length and thickness of the GFRP reinforcement. In doing so, first a parametric finite element study was conducted to evaluate the influence of unidirectional GFRP reinforcement applied onto the arch using eleven possible configurations and different thicknesses. Subsequently, an experimental investigation was conducted to verify the results established by the finite element method as well as the integrity of actual GFRP-reinforced glue-laminated curved structures. The results indicate that GFRP can be considered as an effective and economically viable solution for strengthening and stiffening glulam arches, without adding any appreciable weight to the structure.
\end{abstract}

\section{Introduction}

1.1. Background. Over the past few decades, many studies have been performed on studying the response of fiberreinforced plastic (FRP) laminates when combined with other structural materials such as concrete and wood. An important application of FRP in recent years has been in retrofitting of existing wood, concrete, and steel structural members, such as those used in bridge and other civil structures. Retrofitting structures with FRP is nowadays considered as an effective and economical alternative to the replacement of the structural components, since members are rehabilitated instead of being replaced.

Another advantageous application of FRP has been in increasing the strength of wood beams. Wood is a resilient material, but its relatively low stiffness and statistically varying strength impede its use in long span applications. Gluelaminated technology (hereafter reinforced to as glulam) partially resolves the varying strength issue, but the relatively low stiffness of glulam structural components still impedes their use in moderately large span applications, even when reinforced with composites. This is because while the addition of
FRP can significantly increase the strength, nevertheless, the improvement in stiffness would be marginal.

To alleviate the issue, in one of the earliest studies recorded regarding reinforced wood members, Mark [1] used aluminum strips bonded to the compression and tension faces of wood beams. Failure of the beams occurred mainly by separating and buckling of the aluminum facings. Bohannan [2] reinforced glulam beams of low-grade Douglas-fir using pretensioned steel wire strands in the tension zone. In a similar study, Peterson [3] reinforced low grade Douglas-fir glulam beams with a prestressed flat steel strip bonded in the tension zone. Both studies reported an increase in strength and stiffness for the prestressed beam. Lantos [4] performed an experimental research on glulam beams reinforced with steel bars and found a substantial reduction in the coefficient of variation for bending strength as well as an increase in strength directly proportional to the reinforcement ratio. Krueger and Sandberg [5] studied laminated timber reinforced in the tension zone with a composite of high-strength bronze-coated woven steel wire that was bonded with epoxy.

The use of steel plates for reinforcing glulam beams was studied by Bulleit et al. [6] and was found to be effective, 
achieving remarkable stiffness increase as high as 32 percent and moment capacity increase as high as 30 percent. Although the use of metallic reinforcement has shown promising results with respect to increases in the overall performance of wood products, the issue of inadequate bond between wood and steel reinforcement has been identified as significant problem in such reinforced structures.

Consequently, several researchers considered the use of FRP an effective reinforcing agent for wood structural components. Wangard [7] and Biblis [8] studied the effect of bonding unidirectional fiberglass/epoxy-reinforced plastic to the compression and tension faces of wood cores of various species. Increases in modulus of elasticity (MOE) ranging from 20 to 50 percent using only 10 percent reinforcement by volume were reported. Theakston [9] studied the feasibility of strengthening both laminated and solid wood beams with a fiberglass cloth and woven roving. Increases in loadcarrying capacity ranged from 30 to 60 percent. Theakston observed that even after failure occurred in the wood core, the fiberglass reinforcement retained enough strength to support the load. From a safety standpoint, this observation was an important discovery.

There has also been a renewed interest in past two decades in the application of FRP for reinforcing timber beams. Some examples are Dagher et al. [10], who studied the effect of FRP reinforcements on low-grade eastern Hemlock glulam by fabricating nine glulam beams reinforced with FRP on the tension side and three unreinforced controls. The FRP reinforcement ratios used in his research varied from $0.3 \%$ to $3.1 \%$. All of the glulam beams were tested to failure in four-point bending and the results showed a substantial increase in strength up to $56 \%$ and an increase in stiffness up to $37 \%$ compared to the control beams. Johns and Lacroix [11] investigated the length effect of CFRP (Epoxy) bonded onto the tension side of timber beams (CFRP layer on the full length or on the constant moment area only). Strength increases from 40 to $100 \%$ were reported when compared to the unreinforced control beam. The effect of reinforcement length has also been studied, which indicate that longer reinforcement length shows higher strength for CFRP-reinforced timbers. More failures occurred in the compression side, which indicates a more ductile behaviour. Olsson [12] studied glulam timber arches and developed a method for reliability-based optimization of glulam arches. He then linked his developed method to a commercial software package for optimization of glulam arches.

Radial reinforcement of curved glue-laminated wood beams with composite materials was investigated by Kasal and Heiduschke [13]. The objective of this research was to study the application of fiber-reinforced composite materials in reinforcing laminated wood arches subjected to radial tension. The application of composite materials in radial reinforcement was found to be feasible and possibly advantageous over the glued-in steel rods approach, because of greater flexibility of sizes and properties of reinforcing elements, lower mass, and potential ease of installation.

More recently, Buell and Saadatmanesh [14] also investigated special reinforcement configuration. It consisted of placing CFRP reinforcement at the bottom of the timber beam in the tension side, far from the neutral axis to maximize the bending resistance. The shift of the CFRP was achieved by positioning long pieces of wood to the bottom of the beam. An additional carbon fabric was wrapped around the beam in the side and the tension area. A 69\% increase of the bending strength was reported when compared to the control beam and a compression failure mode. An increase of the stiffness by $18 \%$ was also reported. The increase in mean load capacity was between $44 \%$ and $63 \%$. Moreover, ductile failure mode in compression side was observed in reinforced glulam beams.

As can be seen, there have been several studies conducted in consideration of the performance of GFRP reinforced glulam beams, including those conducted by Yahyaei-Moayyed and Taheri $[15,16]$. In the latter investigations, the creep parameters of aramid fiber-reinforced epoxy (AFRP) and plain wood were determined experimentally. Moreover, a nonlinear finite element model was developed to predict the creep response of the AFRP-reinforced timber beams based on the creep characteristics of the individual components. The results of the finite element analysis showed a good agreement with the experimental results conducted on the AFRP-reinforced samples. Moreover, the influence of reinforcement on the flexural strength of reinforced beams was also examined.

As can be seen from the previous brief survey, the application of FRP in reinforcing other types of glulam structural components is relatively very scarce. An example of such studies is that conducted by Taheri et al. [17], who investigated the response of glue-laminated columns reinforced with GFRP. In that study, the authors conducted a complimentary experimental and computational investigation to characterize the response of axially loaded glulam timber columns strengthened with GFRP. Several parameters such as slenderness ratio, boundary conditions, FRP reinforcement length, and relative cost were considered in that study.

1.2. Motivation. The present work therefore aims at studying the response of GFRP-reinforced glulam three-hinge Tudor arches. The three-hinge Tudor arch is one of the most commonly used curved glulam structural members. They are used in large open structures such as churches, school gyms, warehouses shelters, and barns because of their excellent structural performance and pleasing appearance. The effect of different parameters such as number of layers of laminae and location of the reinforcements on the performance of the arches is investigated in this study.

1.3. Objective. The main objective of this work was to examine the viability of the use of GFRP, a relatively inexpensive composite, in conjunction to inexpensive and relatively low grade wood to produce an effective structural material. The application of the resulting composite into a three-hinge Tudor arch produces a cost-effective and efficient structure. The ultimate goal of this study was to enhance the current engineering database and to provide practical and valuable insight to the designers of wood structures and practicing engineers. The result of this study will partially address the 


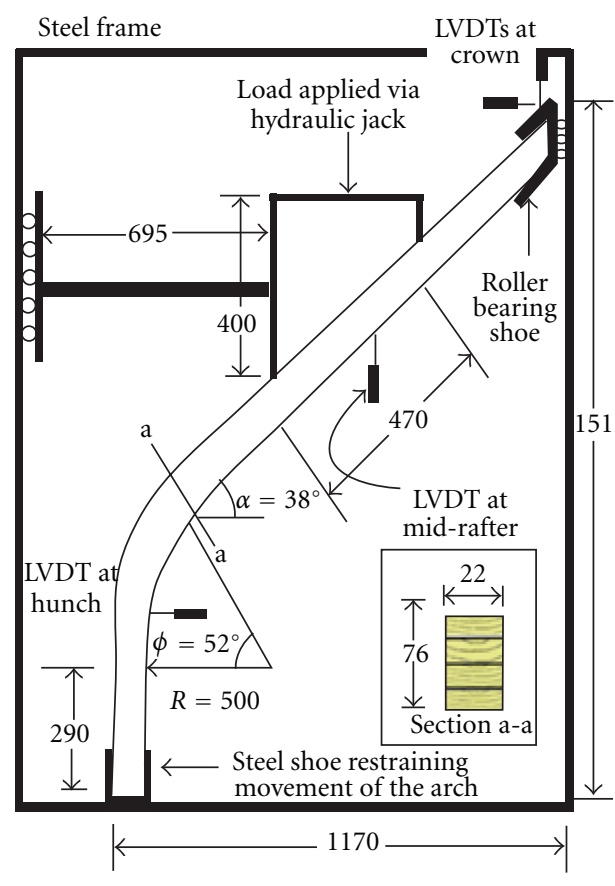

(a)

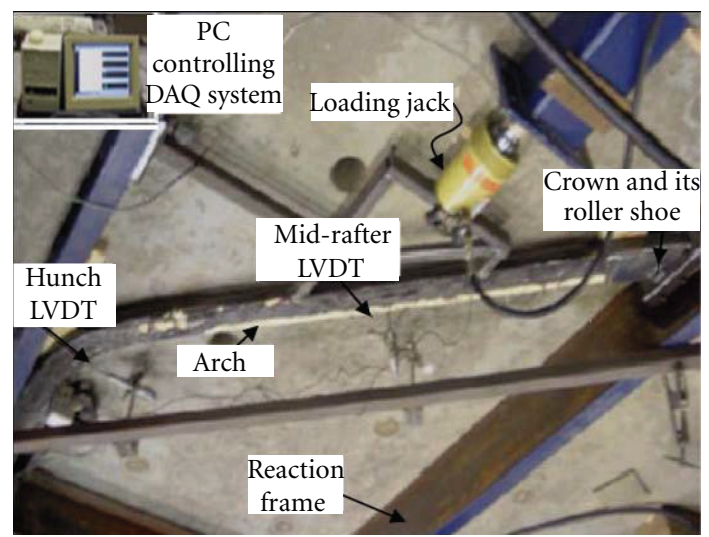

(b)

FIGURE 1: (a) Schematics and dimensions of the test arch specimen and the experimental setup. (b) photo of the actual test setup (drawing not to scale; all dimensions in $\mathrm{mm}$ ).

lack of engineering database in regards to the more diverse applications of FRP when considering wood structures.

\section{Glulam Arch Test Specimens}

2.1. Arch Configuration. In an effort to establish the optimum configuration of GFRP for reinforcing our test arches, the combined loading of dead and snow loads was selected as the loading condition, since this loading condition is one of the most critical loading conditions governing the design of such arches. This paper assumed symmetrical snow load on arch; this indeed is a special case since snow load distribution on arch is not always symmetric. It should be reemphasized that the main objective of this study was to investigate the influence of GFRP reinforcement in enhancing the overall moment capacity and stiffness of Tudor arches, rather than the design aspects of such structures. This loading condition was also selected, because of the resultant symmetry, in that it facilitates easier test setup in laboratory setting as well as optimizes the onerous effort required for the fabrication of the arches tested in this investigation, since only one-half of the arch could be tested to produce the full-arch response. Therefore, the selected loading and arch configuration would facilitate the necessary means to achieve the goal of our study.

2.2. Lumber. The type of wood utilized to construct the glulam arches was eastern white pine, a relatively inexpensive lumber. Both "clear" and "common" grades of the lumber were used in this study. Clear grade is the finest architectural heartwood, which is carefully selected and manufactured to be more or less free of knots and other flaws, and contains sapwood in limited amounts. Common grade is a combination of heartwood and sapwood, containing knots of varying sizes and other slight imperfections. The higher-grade (clear) pine was used to form the other layers (laminations) of the cross section of the arch, where bending stresses are the greatest. The lower-grade (common) pine was used to form the core laminations. The cross section of the glulam arch was $76 \times 22 \mathrm{~mm}^{2}$, with the other dimensions and configuration being illustrated in Figure 1. Since the arch has a hinge on its crown, and the loading combination is symmetric, with the aim of simplifying the investigation, especially arches fabrication, only one-half symmetry of the arch was fabricated and subsequently loaded.

2.3. GFRP Reinforcement Configurations. In order to establish the optimum reinforcement configuration (i.e., the optimized location and length of the GFRP reinforcement along the arch), a total of eleven feasible combinations of GFRP reinforcement (as well as the virgin arch (i.e., with no reinforcement)) were considered in this study. The finite element method was utilized to analyze the various cases and to establish the most optimum reinforcement configuration. Figure 2 shows the various configurations of reinforcements considered in the study. These combinations of reinforcement were selected mainly based on the expected bending moment and shear force variations along the arch. Subsequently, the most promising reinforcement configurations (i.e., cases $(\mathrm{a})$ and $(\mathrm{k})$ ) were considered in our experimental investigation. 


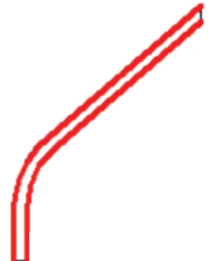

(a)

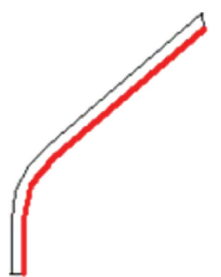

(b)

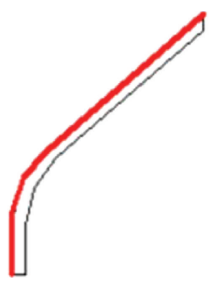

(c)

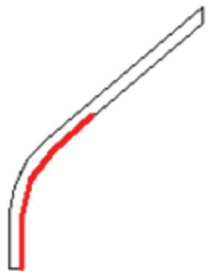

(d)

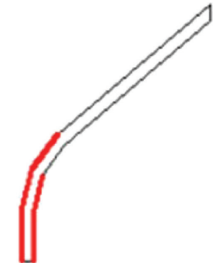

(e)

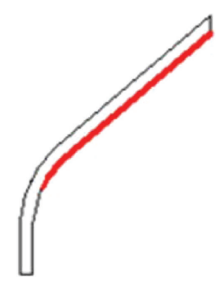

(f)

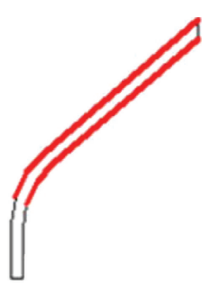

(g)

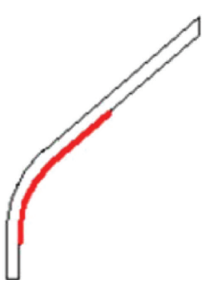

(h)

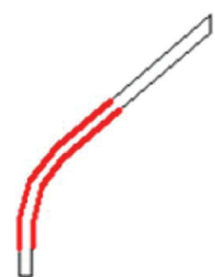

(i)

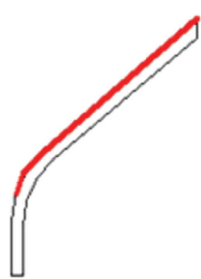

(j)

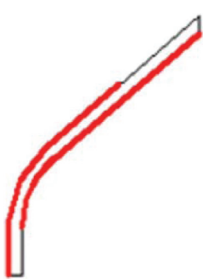

$(\mathrm{k})$

FIGURE 2: Various GFRP reinforcement configurations considered.

The NISA (Numerically Integrated System Analysis), a commercially available finite element package, was employed for this investigation. First-order plane stress element (NKTP1) was used in constructing the models. Some of the mechanical properties of E-glass/vinyl ester composite used to reinforce the arches were obtained experimentally, while the other values were obtained from the available literature. The values are reported in Table 1 . The modulus of elasticity of the glulam section was estimated from the experimental load-displacement curves obtained from testing of nonreinforced glulam arches, reported in Table 1; the other wood properties were obtained through the literature.

Resorcinol (more specifically, CASCOPHEN LT-5210, produced by the Momentive Specialty Chemicals Inc. of Columbus, $\mathrm{OH}$ ), a standard adhesive used in the industry, was used to adhere the lumber pieces as well as adhering the FRP sheets to the arch. The material properties of the Resorcinol used in the analysis were obtained from the supplier's technical sheet and are also summarized in Table 1 .

Results of these analyses, along with the lengths of the reinforcement applied on the top and bottom surfaces of the arch, in each case, have been summarized in Table 2. The locations of the reinforcement configurations are shown in Figure 2. The locations of the combination of FRP reinforcements considered by the finite element method are shown in Figure 2. The results revealed that as expected, the fully reinforced arch, with reinforcement applied on the upper and lower surfaces along the entire arch length (represented by case (a)), produced the highest moment capacity and stiffness. However, this configuration is not the most costeffective alternative. In turn, one can attain relatively very high improvement in load capacity and stiffness by considering the partially reinforced configuration identified as case (k) in Figure 2, while economizing the improvement as well. Consequently, these two configurations were selected for further experimental examination.

2.4. Manufacturing Process. The pine wood material was cut to the required lengths for preparation of the test specimens.
TABLE 1: Material properties used in the analysis.

\begin{tabular}{lccc}
\hline Property & $\begin{array}{c}\text { Easter White } \\
\text { PineGlulam } \\
\text { Lumber* }\end{array}$ & $\begin{array}{c}\text { E-Glass/Vinylester } \\
\text { Composite** }\end{array}$ & $\begin{array}{c}\text { Resorcinol } \\
\text { LT-5210 } \\
\text { adhesive *** }\end{array}$ \\
\hline$E_{11}(\mathrm{MPa})$ & 10500 & 31470 & 3500 \\
$E_{22}(\mathrm{MPa})$ & - & 8807 & 3500 \\
$G_{12}(\mathrm{MPa})$ & 2952 & 2000 & 1500 \\
$v_{12}$ & 0.25 & 0.27 & 0.10 \\
$\begin{array}{l}\text { Shear strength- } \tau_{u} \\
\text { (MPa) }\end{array}$ & & & 16.80 \\
$\begin{array}{l}\text { Peel strength, } \sigma_{u} \\
\text { (MPa) }\end{array}$ & & & \\
$\begin{array}{l}\text { Longitudinal } \\
\text { tensile strength } \\
\text { (MPa) }\end{array}$ & & $550^{*}$ & \\
\hline
\end{tabular}

${ }^{*}$ Values obtained from laboratory tests (Load versus deflection curve).

** Obtained from coupons testing [18].

***Values obtained from Resorcinol Technical Data Sheet.

The arch cross section was constructed using four layers of these pine strips. As stated, two strips of high-grade clear pine laminates were used to form the upper and lower layers of arch's cross section, while two strips of common (knotty) pine were sandwiched in between the two clear strips to form the core of the cross section. These strips were completely immersed in a pool of clean water for a period of 24 hours to make them malleable, so that they could be steamed (to further soften the wood) and bent to shape. The water-saturated lumber strips were subsequently steamed in a chamber for an average of $2.75 \mathrm{hrs}$ per $25 \mathrm{~mm}$ of thickness of the lumber to make them malleable, so they could be bent to the required tight radius of $500 \mathrm{~mm}$. After the completion of the steaming process, the strips were placed into a special jig to facilitate their bending to the specified curvature. The arches were therefore clamped in the jig and let dry for a 24hour period (see Figure 3). Once dried, the strips were then 
TABLE 2: Summary of the finite element results of the twelve models.

\begin{tabular}{|c|c|c|c|c|c|c|}
\hline Cases & $\begin{array}{l}\text { Length of } \\
\text { reinforcement at } \\
\text { top surface }(\mathrm{mm})\end{array}$ & $\begin{array}{l}\text { Length of } \\
\text { reinforcement at the } \\
\text { bottom surface }(\mathrm{mm})\end{array}$ & $\begin{array}{c}\text { Vertical } \\
\text { displacement at } \\
\text { the peak }(\mathrm{mm})\end{array}$ & $\begin{array}{c}\text { Horizontal } \\
\text { displacement at } \\
\text { the haunch }(\mathrm{mm})\end{array}$ & $\begin{array}{c}\text { Vertical } \\
\text { displacement at the } \\
\text { mid-rafter }(\mathrm{mm})\end{array}$ & $\begin{array}{l}\text { von Mises stress at } \\
\text { the haunch }(\mathrm{MPa})\end{array}$ \\
\hline Control & & & -5.34 & -4.32 & -8.96 & 8.44 \\
\hline Case (A) & 2034 & 1973.26 & -3.57 & -2.75 & -5.98 & 4.89 \\
\hline Case (B) & & 1973.26 & -4.27 & -3.36 & -6.64 & 7.80 \\
\hline Case (C) & 2034 & & -4.40 & -3.48 & -6.74 & 4.98 \\
\hline Case (D) & & 770 & -3.99 & -3.17 & -7.22 & 7.98 \\
\hline Case (E) & 873 & 582 & -3.63 & -2.75 & -7.06 & 5.36 \\
\hline Case (F) & & 1390 & -5.03 & -4.01 & -7.23 & 8.21 \\
\hline Case $(\mathrm{G})$ & 1450 & 1390 & -4.93 & -3.94 & -6.45 & 6.66 \\
\hline Case $(\mathrm{H})$ & & 1000 & -4.04 & -3.18 & -7.06 & 7.92 \\
\hline Case (I) & 1060 & 1000 & -4.05 & -3.16 & -6.77 & 5.64 \\
\hline Case (J) & 1452 & & -5.22 & -4.21 & -7.25 & 6.81 \\
\hline Case $(\mathrm{K})$ & 1500 & 1600 & -4.09 & -3.16 & -6.34 & 5.13 \\
\hline
\end{tabular}

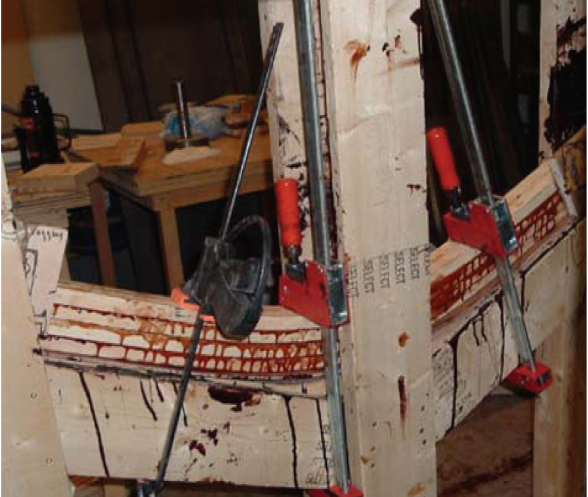

FIGURE 3: Special jig used for bending and gluing the glulam strips.

glued together using liquid Resorcinol mixed with a powder catalyst and clamped and let cured for another 24 hours.

For the reinforcement, two GFRP composite panels with dimensions of $1600 \mathrm{~mm} \times 600 \mathrm{~mm}$ with two unidirectional layup sequences of $[0]_{2}$ and $[0]_{4}$ were manufactured using a vacuum-bagged hand lay-up method. E-glass/vinylester prepreg, supplied by Simex Technologies Inc. (Montreal, Canada), was used to form the composite panels. The laminates were cured in an oven at $145^{\circ} \mathrm{C}$ for 2 hours, per the supplier's specifications. The processed laminate sheets were then carefully cut to $22 \mathrm{~mm}$ strips, using a diamond coated saw. The thickness of the two unidirectional layup sequences of $[0]_{2}$ and $[0]_{4}$ was $0.4 \mathrm{~mm}$ and $0.8 \mathrm{~mm}$, respectively. The tensile properties of the composite were evaluated using appropriate size test coupons according to the method outlined in ASTM D3039-08.

\section{Experimental Investigation}

3.1. Glulam Arch Test Setup. As explained earlier, since the test arch was a three-hinge arch and symmetric with respect to geometry and loading condition with respect to a plane passing through the crown of the arch, the advantage of symmetry was used to test only one-half of the arch. The test program therefore consisted of testing of 15 glulam wood halfarches (hereafter referred to as arches). Three of these 15 halfarches were the control specimens (i.e., nonreinforced glulam arches), while the other 12 specimens were divided into two groups; one group had GFRP reinforcement as per configuration (a), shown in Figure 2, while the other group was reinforced per configuration (k). Each group of 6 arches was further divided into two subgroups, based on the layup of the unidirectional GFRP reinforcements (i.e., $[0]_{2}$ and $[0]_{4}$ ).

The surface areas of the arch, to which the GFRP reinforcement was to be applied to, were sanded and cleaned with compressed air prior to application of the GFRP. The arches were tested in pseudo-four-point bending configuration (see Figure 1). This loading scenario is different from that considered in earlier FE analysis; however, it produces more or less similar deflection and stress patterns on the arch, and is experimentally feasible.

As such, the arch specimen was placed in a reaction steel frame. The load was applied via two rollers attached to stiff subframe, as shown in the figure. This subframe assembly was free to travel vertically on a set of roller-bearings attached to the exterior vertical member of the frame. The load was applied through a hydraulic jack, and a calibrated load cell, with a maximum capacity of $10 \mathrm{kN}$, was placed in between the jack and loading frame to record the exact magnitude of the applied load. Four linear variable displacement transducers (LVDTs) were magnet mounted to the steel frame to measure the displacement of the Glulam arches at various locations, and with the locations of the applied load (see Figure 1). The arches were tested according to the procedures outlined in ASTM D198-84. The test was conducted as displacement controlled, at a rate of $2.0 \mathrm{~mm} / \mathrm{min}$, with data from all transducers being collected simultaneously via a data acquisition system at a sampling rate of $2 \mathrm{~Hz}$, and stored on a personal computer (PC). 


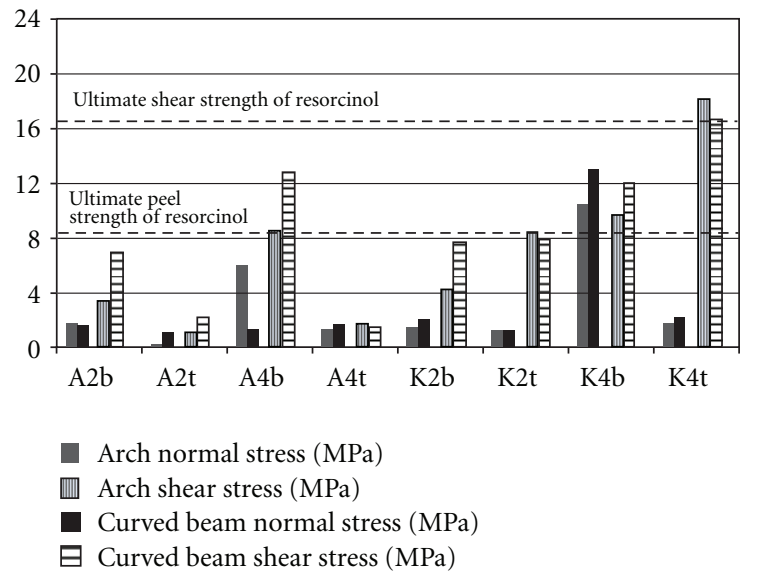

\begin{tabular}{|c|c|c|c|}
\hline ID & Location of interface bond & $\begin{array}{c}\text { Arch/beam } \\
\text { configuration }\end{array}$ & $\begin{array}{c}\text { GFRP } \\
\text { lay-up }\end{array}$ \\
\hline A2b & Bottom layer interface bond & $\mathrm{a}$ & {$[0]_{2}$} \\
A2t & Top layer interface bond & $\mathrm{a}$ & {$[0]_{2}$} \\
A4b & Bottom layer interface bond & $\mathrm{a}$ & {$[0]_{4}$} \\
A4t & Top layer interface bond & $\mathrm{a}$ & {$[0]_{4}$} \\
K2b & Bottom layer interface bond & $\mathrm{k}$ & {$[0]_{2}$} \\
K2t & Top layer interface bond & $\mathrm{k}$ & {$[0]_{2}$} \\
K4b & Bottom layer interface bond & $\mathrm{k}$ & {$[0]_{4}$} \\
K4t & Top layer interface bond & $\mathrm{k}$ & {$[0]_{4}$} \\
\hline
\end{tabular}

Figure 4: Maximum values of the peel and shear stresses within the adhesive along various interface bond lines obtained by FE analyses.

\section{Finite Element Analysis of the Tested Arches}

The NISA finite element package was employed to simulate the response of the tested arches. In total, five sets of analyses were conducted (one for the unreinforced arch, and four for the subgroups of the reinforced arches). The thickness of each layer of GFRP as measured from the manufactured GFRP composite panel was taken as $0.20 \mathrm{~mm}$, and the thickness of the adhesive used to adhere the GFRP to the arch was measured as $0.15 \mathrm{~mm}$. The total depth of wood lamination, interface (glue), and the GFRP reinforcements was measured using a caliper. The thickness of the interface was calculated as the difference of the total depth minus the thickness of GFRP. The glue between wood strips was not significant in the analysis because as soon as the steaming process of strips was finished, the warm strips were taken out from the steam box and were immediately glued and bent by placing them on a special setup, therefore the grain surface at this stage of the wood was easily able to absorb the liquid resinol glue between these strips. Also these strips were closely clamped and left under load for one day and as a result the interface between wood lamination was not visually seen. Moreover, it was observed during testing that there was no delamination occurred between wood lamination and therefore the interface between wood lamination was not indeed considered in this analysis.

The models were constructed using the NKTP1 4-node element. A mesh convergence study was conducted to establish a suitable number of elements and mesh topography.

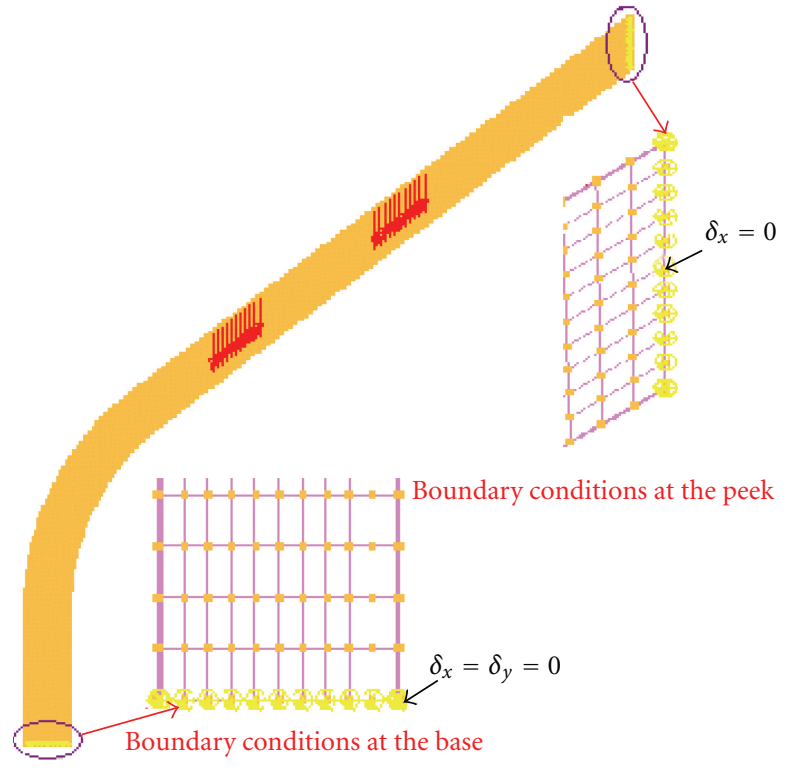

FIgURE 5: Glulam arch finite element boundary conditions.

It should be noted that, as will be explained in the subsequent section, our experimental observation indicated that during the experiments, the half-arches rotated slightly at their crown location, thus violating the assumption of absolute half-symmetry. As a result, two modelling schemes were tried to consider the response of an actual GFRPreinforced Tudor arch as well as mimic the actual arched specimen's response under the laboratory condition. In the first scheme (hereafter referred to as the arch), all the nodes along the vertical plane (at the arch crown) were restrained in the horizontal direction (see Figure 5), thereby modelling a half-symmetry condition. In the other modelling scheme, only the lower node on the plane of symmetry at the crown was restrained in the horizontal direction (see Figure 6). In this configuration, arch's crown allowed to rotate about the restrained node, therefore mimicking the actual rotation of the crown observed during the experiments. This configuration of the arch is referred to as the curved beam configuration hereafter.

In the FE analysis, the failure in the wood was established based on the specified strength for glue-laminated timber for pine, as stipulated by CAN/CSA O86-09. As such, the value of the ultimate compressive strength parallel to grain was taken as $25.20 \mathrm{MPa}$, while the tensile strength parallel to grain value was taken as $13.40 \mathrm{MPa}$. To assess the failure in the GFRP/wood interface, a commonly used second-order criterion was used, represented by the following equation [19]:

$$
\left(\frac{\sigma_{n}}{\sigma_{u}}\right)^{2}+\left(\frac{\tau_{n t}}{\tau_{u}}\right)^{2} \leq 1
$$

where $\sigma_{n}$ represents the normal stress in the adhesive (obtained by FEA). $\tau_{n t}$ represents the shear stress in the adhesive (obtained by FEA). $\sigma_{u}$ represents the peel strength of the adhesive (taken as $8.50 \mathrm{MPa}$, based on supplier's technical sheet). $\tau_{u}$ represents the shear strength of the adhesive (taken as $16.80 \mathrm{MPa}$, based on supplier's technical sheet). 


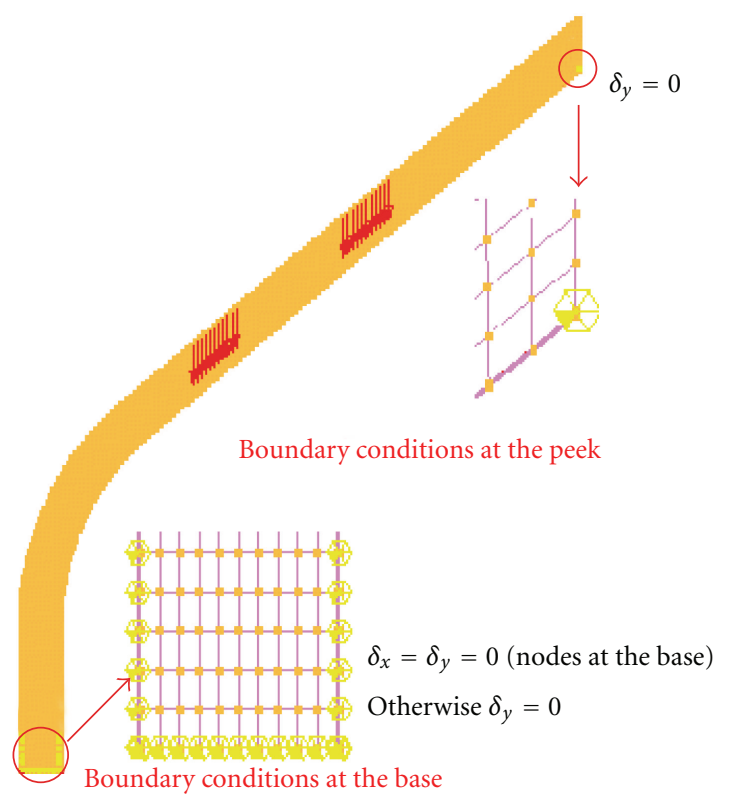

FIGURE 6: Glulam curved beam finite element boundary conditions.

The failure of the GFRP was assessed using the maximum stress theory equation (i.e., $\sigma_{11} / S_{11 \text { (tensile) }} \leq 1$ ), as noted in most composite text book (see e.g., Mallick [19]), using the experimentally obtained value of $550 \mathrm{MPa}$ as the longitudinal tensile strength of GFRP.

The design was based on the lower limit of the previous two criteria. The summary of the results (peel and shear stresses) obtained from the FE analyses has been presented in Figure 4 for the two modelling schemes considered in this study (the arch and curved beam configurations discussed above). Furthermore, the values of the failure limits established by the interface criterion and maximum stress criterion (for the GFRP), as also explained previous, are tabulated in Table 3. As seen, the rotation of the crown significantly influences of the variation in the magnitude of stresses from one configuration to another.

\section{Experimental Results}

5.1. Group 1: Control Glulam Wood Arches. Three unreinforced glulam arches (also referred to as the control arches) were tested to failure, and the resulting ultimate loads, moments, and deflection can be seen in Table 4 . The average ultimate load and the maximum deflection were determined to be $5120.33 \mathrm{~N}$ and $13.30 \mathrm{~mm}$, respectively.

The load versus mid-rafter deflection curves are illustrated in Figure 7. It can be seen that the three control arches performed similarly as seen by the initial slope of the load- deflection curves as well as the ultimate capacities. Both controles arches 1 and 2 sustained loads at approximately 5,197 $\mathrm{N}$ and 5,014 $\mathrm{N}$ with the maximum mid-rafter displacements of $13.60 \mathrm{~mm}$ and $13.90 \mathrm{~mm}$, respectively. The third control arch sustained 5,150 $\mathrm{N}$ of load with the least displacement of $12.50 \mathrm{~mm}$ compared to the arches 1 and 2. The maximum displacement of the three control arches occurred at the mid-rafter point before the final failure of the specimens. All beams failed in Tension. After the glulam arches were tested to failure, the modulus of elasticity of each one was calculated by using the linear portion from its load deflection curve. Because of the inherent heterogeneity of wood, it would be impractical to attempt to predict the ultimate load of such structures using the linearly elastic finite element method. The average ultimate load of each group obtained from the experimental testing was used in the finite element program as an indicator requesting the program to quit as soon as the load applied surpassed that given load. The deflections data obtained from the FE analysis were compared with those obtained from the experiment. Finite element analysis showed good agreement to the experimental results. The mode of failure in all three specimens was initiated by development of a crack at the haunch of the arch, where the bending moment was the maximum.

Finite element prediction showed good agreement to the experimental results obtained. The mode of failure in all three specimens was initiated by development of a crack at the haunch of the arch, where the bending moment was the maximum.

5.2. Partial Reinforcement of Glulam Wood Arch (Configuration $(K)$ ). As stated earlier, this group contained of six arches, which were further subdivided into two sets of three half-arches. The first set comprised of the partially reinforced (configuration $(\mathrm{K})$ ), with the $[0]_{2}$ unidirectional GFRP being applied on the upper and lower surfaces of the half-arches. The second set of arches was also partially reinforced, but with four layers of GFRP (i.e., $[0]_{4}$ ). The load versus midrafter deflection of two of the arches and the FE results are illustrated in Figure 8. The third arch was not tested, since there was a visible manufacturing flaw, which had occurred inadvertently during its fabrication.

The failure mode of this set of GFRP-reinforced arches was different from that observed for the unreinforced (control) set. Brittle mode cracking was heard and observed during various loading stages, and the failure occurred rather catastrophically and without any warning, when the load reached to the highest recorded load value. At that stage, a delamination in the interface of the GFRP and glulam arch became evident at the midpoint of the rafter, which was followed by a sudden failure of the lower most layer of wood.

As it can be seen from Table 4, the comparison of the average ultimate capacity of the partial reinforcement of set 1 showed 30.78 percent improvement in strength. The stiffness, EI, was calculated from the initial linear elastic portion of each curved beam's load-deflection curve, using the conventional beam deflection equation, established based on the virtual-work method. The stiffness was found to have increased by 9.7 percent in comparison to that of the control arch.

The partially reinforced arches with four layers of GFRP (set 2 of group 2) were tested as well, and all of them were delaminated before the load reached an average of 3,600 N. In all arches, delamination of GFRP from wood occurred at the upper surface of the arch, at the free edges near to the location of the applied load. Another distinct delamination 
TABLE 3: Comparison of the maximum values obtained by the use of failure criteria for the adhesive interface and GFRP obtained by FE analysis.

\begin{tabular}{|c|c|c|c|c|}
\hline & Adhesive Inte & $\left.\left(\tau_{n t} / \tau_{u}\right)^{2} \leq 1\right)$ & GFRP & $<1)$ \\
\hline & {$[0]_{2}$} & {$[0]_{4}$} & {$[0]_{2}$} & {$[0]_{4}$} \\
\hline Location of st & & & & \\
\hline & & GFRP con & & \\
\hline Arch-lower & 0.80 & 8.81 & 0.21 & 0.2 \\
\hline Beam-lower & 0.96 & 1.86 & 0.21 & 0.2 \\
\hline Arch-upper & 0.014 & 0.47 & 12.30 & 13.79 \\
\hline Beam-upper & 0.34 & 0.65 & 12.82 & 12.29 \\
\hline & & GFRP con & & \\
\hline Arch-lower & 0.66 & 25.65 & 0.15 & 0.16 \\
\hline Beam-lower & 1.36 & 39.64 & 0.22 & 0.23 \\
\hline Arch-upper & 0.99 & 3.70 & 0.15 & 0.16 \\
\hline Beam-upper & 0.91 & 3.61 & 0.22 & 0.2 \\
\hline
\end{tabular}

Arch/beam-lower: FRP applied onto the lower face of the arch/Beam.

Arch/beam-upper: FRP applied onto the upper face of the arch/Beam.

TABLE 4: Experimental and finite element analysis results of the control glulaminated curved beams and arches (average values of the test results described in the text).

\begin{tabular}{|c|c|c|c|c|c|}
\hline & $\begin{array}{l}\text { Average ultimate } \\
\text { Load }(\mathrm{N})\end{array}$ & $\begin{array}{c}\text { Horizontal } \\
\text { displacement at } \\
\text { hunch }(\mathrm{mm})\end{array}$ & $\begin{array}{c}\text { Vertical } \\
\text { displacement at } \\
\text { mid-rafter }(\mathrm{mm})\end{array}$ & $\begin{array}{c}\text { Horizontal } \\
\text { displacement at } \\
\text { crown }(\mathrm{mm}) \\
\end{array}$ & $\begin{array}{c}\text { Vertical } \\
\text { displacement at } \\
\text { crown }(\mathrm{mm})\end{array}$ \\
\hline & \multicolumn{5}{|c|}{ Control arches } \\
\hline Experimental & \multirow{2}{*}{5,120} & 1.13 & -13.3 & -5.01 & -0.41 \\
\hline \multirow[t]{2}{*}{ FEA } & & 0.25 & -12.01 & -3.41 & -2.10 \\
\hline & \multicolumn{5}{|c|}{ Fully GFRP-reinforced arches_-configuration (a) } \\
\hline Experimental & \multirow{2}{*}{8,100} & 0.42 & -20.14 & -4.80 & -3.62 \\
\hline \multirow[t]{2}{*}{ FEA } & & 1.50 & -15.40 & -3.70 & -3.21 \\
\hline & \multicolumn{5}{|c|}{ Partially GFRP-reinforce arches_-configuration (k) } \\
\hline Experimental & \multirow{2}{*}{6,696} & 0.60 & -18.12 & -1.41 & -1.23 \\
\hline FEA & & 0.35 & -15.10 & -3.81 & -2.21 \\
\hline
\end{tabular}

The noted horizontal displacement at crown was measured at the highest point on the arch/beam (see Figure 1).

occurred at the end of the same reinforcement. The delamination in the interface between the GFRP and the wood occurred when the applied load reached $3,600 \mathrm{~N}$, as seen from the typical graph presented in Figure 8.

\subsection{Full-Length Reinforcement of Glulam Wood Arch (Con-} figuration (A)). Group 3 also contained six arches divided into two sets of three arches each. The first set was fully reinforcement with $[0]_{2}$ layup of unidirectional GFRP being applied on the upper and lower surfaces of the arches along the entire length. The second set was reinforced in the same way as the first set, except with $[0]_{4}$ layup of GFRP.

Figure 9 illustrates the Load versus mid-rafter deflection response of the two arches in set 1 of group 3. The third arch prematurely failed due to delamination of its reinforcement, due to manufacturing cause anomaly (lack of adhesive penetration in some sections).

As can be seen from Table 4, this set of curved beams exhibited 42 percent increase in the ultimate load carrying capacity as well as 27 percent increase in their stiffness, compared to the unreinforced (control) arches. The mode of failure in these arches was different from that observed in the partially reinforced cases. No visible cracks could be observed during the experiments. The response of the arch was elastic up to approximately $90 \%$ of its ultimate load carrying capacity, after which the response was relatively fairly ductile, with a rather plasticity-like response, up to the ultimate load. After reaching the ultimate load carrying plateau, the arches could no longer sustain further loading, and the load gradually decreased. This type of ductile response is highly desirable, since it provides warning before the final failure. 


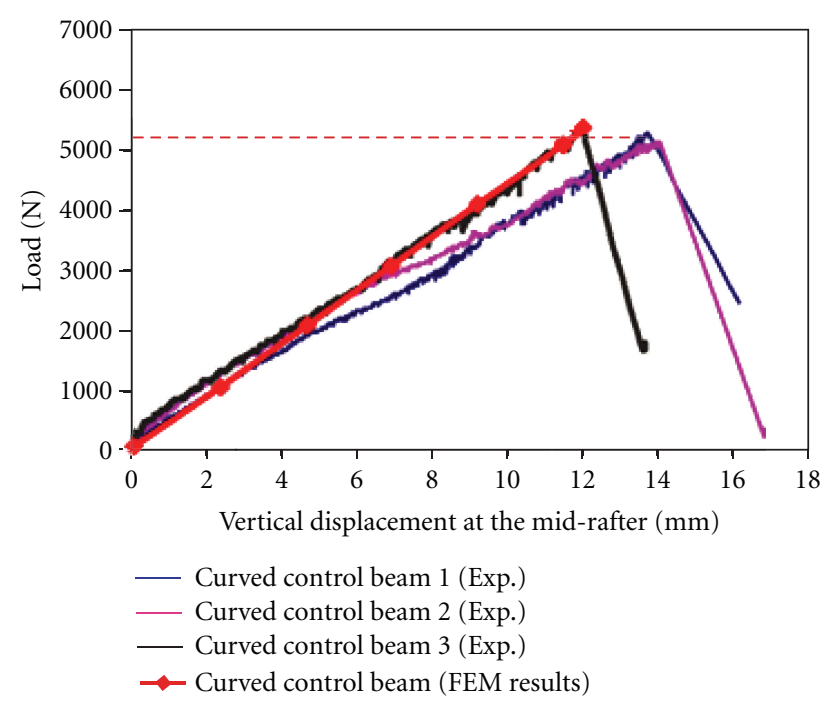

FIGURE 7: Load versus displacement of the three control arches and that obtained from FEA.

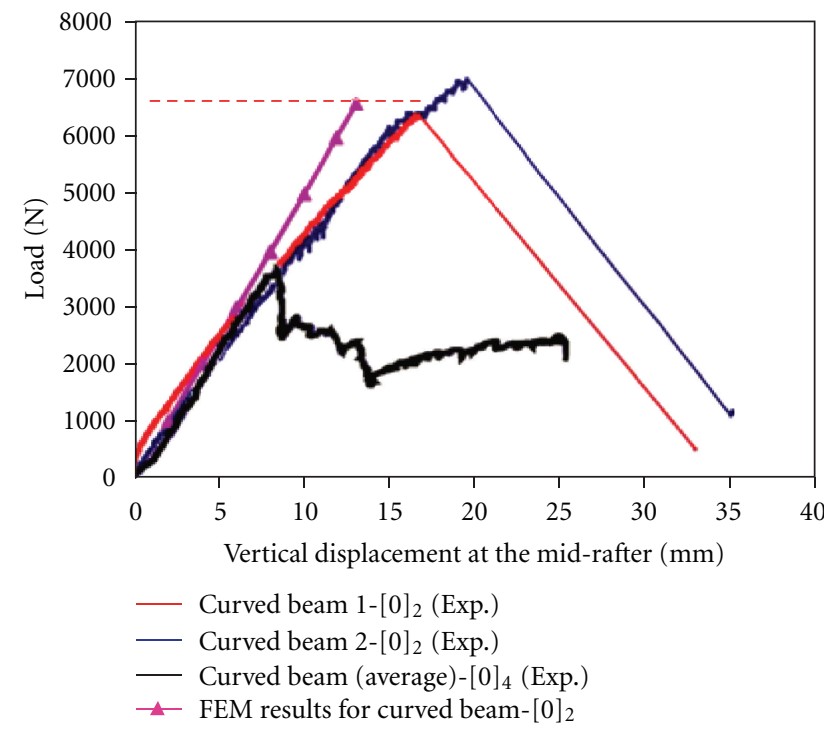

FIGURE 8: Typical load-displacement curves of the half-arch (case K) with two and four layers of partial reinforcement compared to the FEM results.

The fully reinforced arches with four layers of GFRP in set 2 of group 3 were also tested. Similar to the partially reinforced arches, they all failed prematurely due to delamination of the GFRP from the arch, as well as within the wood layers, which occurred at an average load of $4000 \mathrm{~N}$, as can be seen from Figure 9. The failure mode occurred in twofold: (i) by delamination of wood layers at region close to the support at the foot of the arches, followed by (ii) delamination of GFRP from arches in the region in between the two concentrated applied loads.

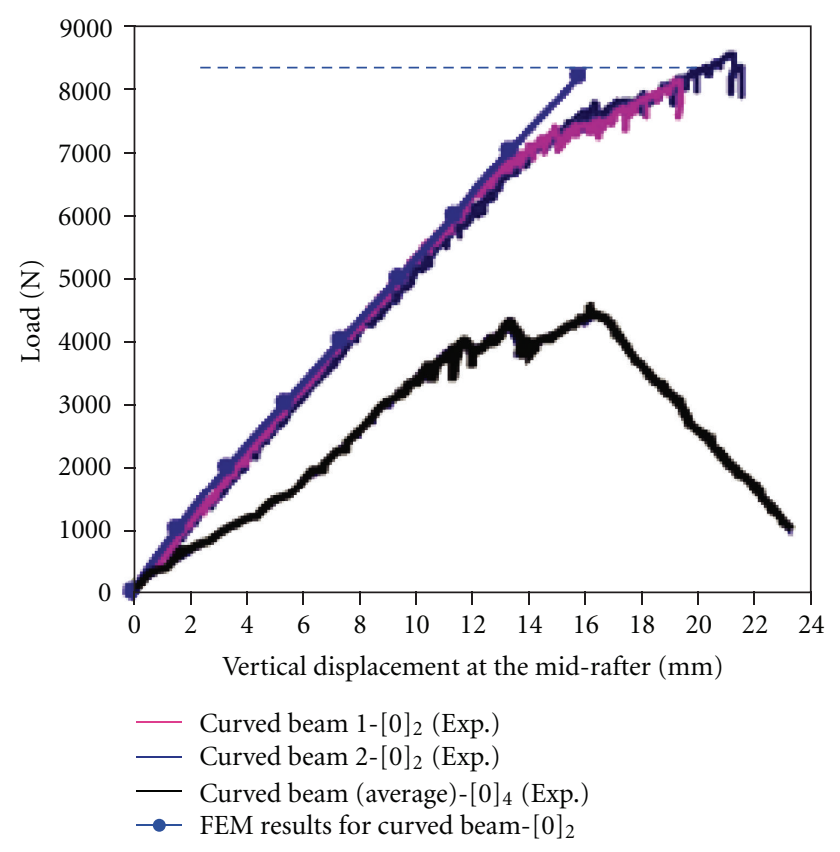

FIgURE 9: Typical load-displacement curves of the half-arch (case A) with two and four layers of full-length reinforcement compared to the FEM results.

\section{Discussion on the Results}

The results of the vertical and horizontal displacement obtained from the finite element analyses of the curved beam and arch models compared to the experimental values are tabulated in Table 4 . The computational results agree well with the experimental results. The comparison of the computational results for the two modeled boundary conditions confirmed that, contrary to what was initially anticipated, the half-arches reacted like a curved beam. This was primarily due to the excessive rotation of the crown caused by the application of nonuniform loading (despite the fact that the resulting bending moment distribution due to the uniformly distributed load and the concentrated loading scheme were established to be more or less similar).

The finite element analyses results presented in Table 3 also indicated that delamination would occur due to the presence of very high shear stress in some portions of GFRPwood interface, especially when the arch was reinforced with a laminate comprised of four layers of GFRP (i.e., $[0]_{4}$ ), regardless whether the GFRP reinforcement was applied along the entire length of the arch or along the partial length. This shortfall could be better addressed by using a suitable epoxy adhesive, as opposed to the resorcinol used in this project (which is commonly used by the glulam industry). Resorcinol is a relatively strong, but very brittle adhesive. The glulam arches tested in this study underwent relatively large magnitude of deformation; as a result, large shearing and peel stresses were developed within the adhesive interface of the arch and GFRP reinforcement. The thicker GFRP (i.e., $[0]_{4}$ ) had significantly higher stiffness than the thinner GFRP $\left([0]_{2}\right)$, thus, producing larger strain incompatibility within 
the resorcinol interface. This caused premature failure of the resorcinol adhesive layer in those cases.

\section{Conclusions}

Through a computational investigation, the two most effective configurations of GFRP reinforcement for strengthening and stiffening glue-laminated Tudor arch were established; one configuration was to apply the GFRP reinforcement on the upper and lower surfaces of the cross-section along the entire length of the arch (configuration (a) in Figure 2); the other was the application of the reinforcement along the partial length of the arch (configuration $(\mathrm{k})$ in Figure 2). It was found that the thickness of the GFRP was the most significant factor in limiting the performance of the GFRP reinforcement. Interestingly, thicker reinforcement caused premature delamination of GFRP from the wood.

The following summarizes the findings of this study.

(i) The average ultimate load for a glulaminated curved beam with $[0]_{2}$ layup (i.e., GFRP reinforcement ratio of $1.05 \%$ by volume) applied on the upper and lower surfaces of the arch/curved beam, along the fulllength of the arches, showed an increase of 42 percent in strength and a 27-percent increase in stiffness compared to those of the control curved beam, respectively. This remarkable enhancement was achieved by using only $1 \%$ by volume of reinforcement. There were no clear cracks or delamination in the structure with this reinforcement configuration up to the stage when the applied load approached the ultimate load. When the load exceeded the values corresponding to the yield strength of the materials, the specimens reinforced with GFRP along their full-length (configuration (a)) exhibited gross plastic-like deformation. The resulting deformation was permanent upon release of the load. This type of failure is the preferred mode, since it provides warning before the final failure.

(ii) All GFRP glulam-curved beams reinforced with $[0]_{4}$ layup GFRP (with a reinforcement ratio of $2.10 \%$ by volume) also applied along the full-length of the arches delaminated before the load reaching approximately 80 percent of the ultimate load carried by the control glulam-curved beams. This was prompted due to excessive shear and peel stresses in the adhesive layer joining wood to GFRP.

(iii) The ultimate load for the glulaminated curved beam reinforced with $[0]_{2}$ layup of GFRP applied along the partial length exhibited a 30.80-percent increase in strength and a 9.70-percent increase in stiffness, compared to the control glulam-curved beam. Cracks occurred without any warning, immediately after the curved beam reached its ultimate load carrying capacity, at which stage, a very strong blast occurred at the lower side of the cross section, followed immediately by delamination of the GFRP from the wood.

(iv) In the partially reinforced curved beams reinforced with $[0]_{4}$ layup GFRP, the failure occurred by at the interface between the wood and the GFRP at a load 27 percent less than the ultimate load of the control curved beams. The delamination occurred as a result of large combined shear and peel stresses developed at the free edges of the reinforcement that was adhered to the bottom surface of the curve beams.

\section{References}

[1] R. Mark, "Wood-aluminium beams within and beyond the elastic rangepart1: rectangular sections," Forest Products Journal, vol. 10, no. 11, pp. 477-484, 1961.

[2] B. Bohannan, "Pre stressed wood members," Forest Products Journal, vol. 12, no. 12, pp. 596-602, 1962.

[3] J. Peterson, "Wood beams prestressed with bonded tension elements," Journal of Structural Engineering, vol. 91, no. 1, pp. 103-119, 1965.

[4] G. Lantos, "The flexural behaviour of steel reinforced laminated timber beams," Wood Science, vol. 2, no. 3, pp. 136-143, 1970.

[5] G. P. Krueger and L. B. Sandberg, "Ultimate strength design of reinforcing timber "evaluation of design parameters"," Wood Science, vol. 6, no. 4, pp. 316-330, 1974.

[6] W. Bulleit, L. Sandberg, and G. Woods, "Steel-reinforced glued laminated timber," Journal of Structural Engineering, vol. 115, no. 2, pp. 433-444, 1989.

[7] F. Wangard, "Elastic deflection of wood-fiber-glass composite beams," Forest Products Journal, no. 14, pp. 256-260, 1964.

[8] E. J. Biblis, "Analysis of wood fibre glass composite beams within and beyond the elastic region," Forest Products Journal, vol. 15 , no. 2 , pp. $81-88,1965$.

[9] F. H. Theakston, "A feasibility study for strengthening timber beams with fibreglass," Canadian Agricultural Engineering, vol. 7, no. 1, pp. 17-19, 1965.

[10] H. J. Dagher, T. E. Kimball, and S. Shaler, "Effect of FRP reinforcement on low grade Eastern Hemlock," in Proceedings of the National Conference on Wood-Transportation Structures, United States Department of Agriculture, Forest Service, Forest Products Laboratory, Madison, Wis, USA, 1996.

[11] K. C. Johns and S. Lacroix, "Composite reinforcement of timber in bending," Canadian Journal of Civil Engineering, vol. 27, no. 5, pp. 899-906, 2000.

[12] N. Olsson, Glulam timber arches strength of splices and reliability-based optimization, Ph.D. thesis, Lulea University, Luleå, Sweden, 2001.

[13] B. Kasal and A. Heiduschke, "Radial reinforcement of curved glue laminated wood beams with composite materials," Forest Products Journal, vol. 54, no. 1, pp. 74-79, 2004.

[14] T. W. Buell and H. Saadatmanesh, "Strengthening timber bridge beams using carbon fiber," Journal of Structural Engineering, vol. 131, no. 1, pp. 173-187, 2005.

[15] M. Yahyaei-Moayyed and F. Taheri, "Creep response of gluedlaminated beam reinforced with pre-stressed sub-laminated composite," Construction and Building Materials, vol. 25, no. 5, pp. 2495-2506, 2011.

[16] M. Yahyaei-Moayyed and F. Taheri, "Experimental and computational investigations into creep response of AFRP reinforced timber beams," Composite Structures, vol. 93, no. 2, pp. 616-628, 2011.

[17] F. Taheri, M. Nagaraj, and P. Khosravi, "Buckling response of glue-laminated columns reinforced with fiber-reinforced plastic sheets," Composite Structures, vol. 88, no. 3, pp. 481490, 2009. 
[18] ASTM, "Standard test method for the tensile properties of polymer matrix composite materials," Tech. Rep. ASTM D3039M-08, American Society for Testing and Materials, Conshohocken, Pa, USA, 2008.

[19] P. K. Mallick, Fiber-Reinforecd Composites: Materials, Manufacturing, and Design, Marcel Dekker, New York, NY, USA, 1993. 

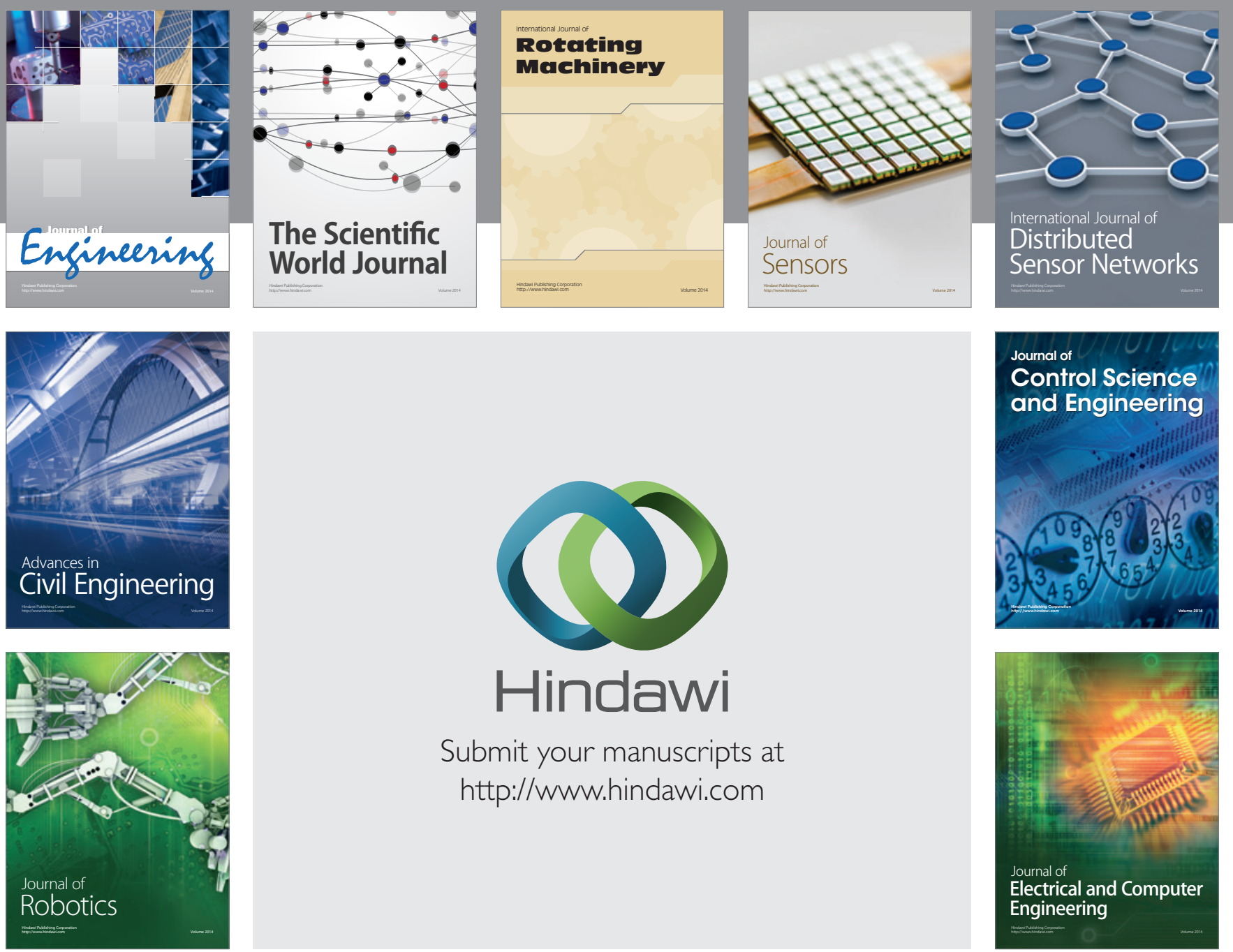

Submit your manuscripts at

http://www.hindawi.com
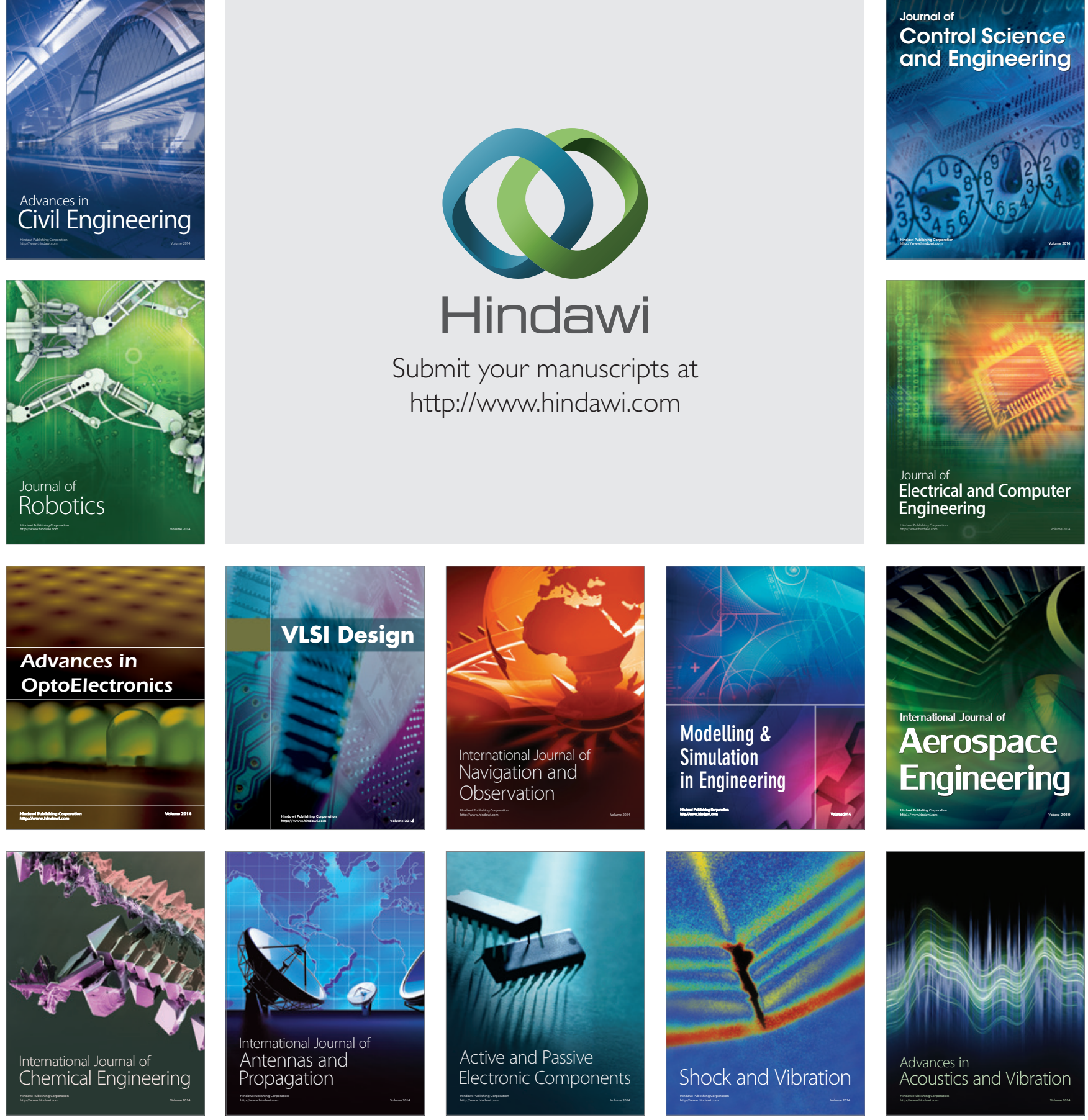